\section{Abstract}

\title{
Effects of early and late life environments on ageing
}

\author{
Krish Sanghvi, Maider Iglesias-Carrasco, Felix Zajitschek, Loeske E.B. Kruuk, Megan L.
}

Head

Early and late life environments can interact in complex ways to influence the fitness of individuals. Most studies investigating effects of the environment on fitness focus on environments experienced and traits expressed at a single point in an organism's life.

However, environments vary with time, thus the environments organisms experience at different ages may interact to affect how traits change throughout life. Here, we test whether thermal stress experienced during development leads individuals to cope better with thermal stress as adults. We manipulated temperature during both development and adulthood and measured a range of life-history traits, including senescence, in male and female seed beetles, Callosobruchus maculatus. We found that favourable developmental conditions increased reproductive performance of females (i.e. silver-spoon effects). In contrast, non-reproductive traits such as lifespan and survival senescence were only affected by adult environments- high adult temperatures decreased longevity and survival. Additionally, developmental and adult environments interacted to affect age-dependent changes in male weight. Overall, our results show that effects of early and late environments can be both sex- and trait- specific, and that a full understanding of how environments interact to affect fitness and ageing requires the integrated study of conditions experienced during different stages of ontogeny.

Keywords: silver-spoon effect, matching environments, phenotypic plasticity, beneficial acclimation, Callosobruchus maculatus, senescence. 


\section{Introduction}

25 Early life conditions can act directly on developing phenotypes and in consequence

26 can have both immediate and long-lasting effects on a range of fitness-related traits

27 (Frankenhuis et al, 2019, van de Pol, Bruinzeel et al, 2006). For example, various studies (e.g.

28 Descamps et al, 2008; Klepsatel et al, 2019, 2020; Madsen \& Shine, 2000; Muller et al, 2016;

29 Sanghvi et al, 2021; Wong \& Kolliker, 2014) have shown that developmental environments

30 can create "silver-spoon effects" (Grafen, 1988; Monaghan, 2008), where individuals who

31 experience a favourable early environment have increased fitness and performance as adults,

32 compared to individuals who experience poor developmental conditions.

33 The effects of early life environments on fitness are also expected to depend on

34 conditions experienced later in life (Gluckman et al, 2005, Monaghan, 2008). It has been

35 suggested that individuals experiencing certain conditions during development may adjust

36 their phenotype to improve performance when exposed to the same conditions as adults

37 ("environmental matching" or predictive adaptive response). Under this scenario, early life

38 conditions shape the phenotype in response to predicted adult conditions, so that fitness is

39 optimised when environments experienced during development and adulthood match

40 (Bateson et al, 2014; Beaman et al, 2016; Cleal et al, 2007; Hayward \& Lummaa, 2013). A

41 special case of the environmental matching hypothesis, the "beneficial acclimation" response,

42 (Huey et al, 1999; Woods \& Harrison, 2002), deals explicitly with stressful developmental

43 and adult temperatures. It predicts that stressful temperatures experienced during development

44 acclimate individuals so they perform better when they also experience these stressful

45 temperatures as adults, compared to individuals who only experience stress as adults and not

46 during development (e.g. Bahnrdoff et al, 2016; Deere \& Chown, 2006; Kellermann et al,

47 2017; Kristensen, 2008; Scharf et al, 2015; Scott \& Johnston, 2012). Another hypothesis 
which predicts that adult environments are important for determining later life fitness

consequences of early life environments is the "environmental saturation" hypothesis

(Engqvist \& Reinhold 2016; Pigeon et al, 2019). This hypothesis predicts that in favourable

adult environments, all individuals will perform well regardless of their developmental

environment, and likewise, that all individuals will perform poorly in bad adult environments.

Thus, effects of developmental environments on adult phenotypes are only evident in intermediate adult environments (e.g. Pigeon et al, 2019).

Empirical evidence from studies looking at how early and late life environments interact to affect adult traits is not clear cut, and indicates that the various hypotheses employed to explain the relationships between phenotypic and environmental variation are not mutually exclusive (Pigeon et al, 2019). For instance, some studies find evidence for beneficial environmental matching (Duxbury \& Chapman, 2020), while others find other types of interactive (Briga et al, 2017), or only additive (Kleinteich et al, 2015) effects of exposure to poor conditions during both early and late life. Additional complexity to the tangled interactions between early and late life conditions arises from the fact that responses to environmental stimuli can be trait- and sex-dependent (e.g. Duxbury \& Chapman, 2020; Helle et al, 2012; Krause et al, 2017; Min et al, 2020; Pigeon et al, 2019; Santos et al, 2021; Scharf, Braf et al, 2015; Stillwell \& Fox, 2005). For example, in cichlids reproductive rate is determined only by nutrition during development, while adult growth rate is determined only by nutrition in the adult stage, and clutch size is determined by both developmental and adult life nutrition (Taborsky, 2006). Differences in the way the environment affects different traits may result from energetic and physiological constraints acting on life-history traits (Partridge and Silby 1991), as well as the necessity to allocate resources across traits. Furthermore, differences between males and females in their life-histories and mating strategies mean that selection might favour males and females to respond differently to the same environment (Ceballos \& Valenzuela 2011; Maklakov et al, 2009; Stillwell et al. 2010). For example, in 
74 seed beetles, males and females respond differently to the presence and density of competitors

75 during the larval stage, leading to sex-specific differences in a variety of life-history traits

76 (Iglesias-Carrasco et al 2020; Sanghvi et al, 2021).

77 Research shows that, in addition to influencing the absolute expression of traits, the

78 environment can also influence how traits change over an individual's life, and specifically

79 how they deteriorate with advancing age (i.e. how they senesce) (Balbontin \& Moller, 2015;

80 Nussey et al, 2007). Senescence occurs as a consequence of relaxed selection on fitness-

81 related traits in older individuals due to trade-offs between life-history components (Rose \&

82 Charlesworth, 2002; Stearns, 1989). However, the rate at which individuals age may depend

83 on a range of factors such as their sex and external environment (e.g. Sanghvi et al, 2021).

84 While there is some support for silver-spoon effects on ageing, with favourable

85 developmental conditions leading to slower reproductive and survival senescence (Hayward,

86 Wilson et al, 2013, Cooper and Kruuk, 2018, Sanghvi et al, 2021), an alternative hypothesis

87 suggest that individuals experiencing good environments may senesce faster due to increased

88 investment in growth and reproduction when young (Adler et al, 2016; Hooper et al 2017;

89 Hunt et al, 2004; Spagopoulou et al, 2020). Additionally, senescence can also depend on the

90 interactions between developmental and adult environments, as seen in studies which test for

91 compensatory growth. Here, organisms which experience poor developmental environments

92 increase their investment in growth in favourable adult environments, although at the cost of

93 increased mortality (Dmitriew \& Rowe, 2007; Metcalfe \& Monaghan, 2001). While recent

94 research has begun investigating how interactions between developmental and adult

95 environments affect survival and reproductive senescence (Duxbury \& Chapman, 2020; Min

96 et al, 2021; Zajitschek et al, 2009), the results do not clearly support one hypothesis (silver-

97 spoon, matching environment, or environmental saturation). Additionally, the age-dependent

98 changes in traits measured are restricted to survival and reproduction, and do not consider

99 other traits which can also change with age and influence fitness. 
101 development and adulthood, if present, are beneficial or not, on various life-history traits,

102 including senescence, in male and female seed beetles (Callosobruchus maculatus).

103 Temperature is known to be crucial in determining life-history traits, including senescence,

104 and physiology of ectotherms (Zuo et al, 2012) and is often manipulated in studies which test

105 for silver-spoon effects (e.g. Scharf, Braf et al, 2015), matching environments (e.g. Min et al,

106 2021), and beneficial acclimation (e.g. Leroi et al, 1994), making it ideal for our experiment.

107 In seed beetles, hot temperatures have been shown to be stressful to survival and reproduction

108 (Fox et al, 2011; Stillwell \& Fox, 2005; Stillwell et al, 2007; Vasudeva et al, 2014). However,

109 it is unknown how unfavourable temperatures at different life stages interact with each other

110 to affect senescence, and whether these interactions can be beneficial.

\section{Methods}

113 Origin and maintenance of study species

114 Our stock population of C. maculatus was sourced in 2017 from stock kept at the

115 University of Western Australia (see Dougherty et al, 2017 for maintenance details). Once in

116 our lab, stock was maintained for 14-16 generations on cowpea beans (Vigna unguiculata) at

$11724^{\circ} \mathrm{C}-28^{\circ} \mathrm{C}$ and $20 \%-40 \%$ relative humidity. Neither stock nor experimental beetles were

118 provided food or water as adults because they do no need to feed or drink as adults in order to

119 survive and reproduce (Beck \& Blumer, 2014).

Experimental design

122 To test the effects of developmental and adult temperatures on life-history traits and

123 senescence, we used a split-brood full-sib $2 \times 2$ factorial design, in which beetles were assigned

124 to either 'ancestral' temperatures $\left(23^{\circ} \mathrm{C}-25^{\circ} \mathrm{C}\right)$ or 'hot' temperatures $\left(33^{\circ} \mathrm{C}-36^{\circ} \mathrm{C}\right)$ during 
125 development, and then ancestral or hot temperatures as adults. The ancestral temperature was

126 at the lower end of the temperature range in which the stock had been raised for over 14-16

127 generations. The hot temperature was a novel and unfavourable environment for this

128 population.

129 To breed experimental beetles, we collected 86 male and 86 female virgin seed beetles

130 from 150 isolated stock beans, within an hour from when they emerged. Virgin females were

131 randomly paired with virgin males for mating and then given 20-30 beans on which to lay

132 eggs (at $24^{\circ} \mathrm{C}$ ). The beans were checked for eggs every two hours, and those with a single egg

133 laid on them were transferred to individual Eppendorf tubes. If a bean had more than one egg

134 laid on it, the extra eggs were scraped off. Eppendorf tubes containing a bean with an egg,

135 were then randomly assigned to a hot $\left(33^{\circ} \mathrm{C}-36^{\circ} \mathrm{C}\right)$ or ancestral $\left(23^{\circ} \mathrm{C}-25^{\circ} \mathrm{C}\right)$ developmental

136 temperature for incubation until adults emerged.

137 On the day of emergence, beetles were weighed (to the nearest $0.01 \mathrm{mg}$ ) using a

138 Sartorius Cubis microbalance, and their developmental time (in days) and sex were recorded.

139 Beetles were then assigned to either the hot or ancestral adult temperature treatment, in which

140 they remained until they died. This generated four treatments: ancestral developmental and

141 ancestral adult $(\boldsymbol{A A})$, ancestral developmental and hot adult $(\boldsymbol{A H})$, hot developmental and

142 ancestral adult $(\boldsymbol{H A})$, and hot developmental and hot adult $(\boldsymbol{H H})$ temperatures (See Table S1

143 in Supplement for sample sizes). Males were kept in Eppendorf tubes and weighed every

144 second day. Females were individually mated with a single male from our stock population on

145 the day of their emergence, then transferred to a Petri dish and given 15 new beans each day

146 to lay eggs on. To ensure that all females mated, we observed whether or not the female

147 kicked the male with her hind legs to end copulation (if she did not, we paired her with the

148 same male again after 20 minutes). Beans with eggs laid on them were stored in plastic bags,

149 and frozen at $-20^{\circ} \mathrm{C}$ for counting later. Both sexes were checked daily for survival and their

150 adult lifespan was recorded. Details of all traits measured are given in Table 1. 
152 Blocks 2 and 3: 30 families each). The individuals used in the three experimental blocks came

153 from 3 successive generations of stock beetles (i.e. blocks 1, 2, and 3, correspond to

154 generations 14,15 , and 16 respectively). Some experimental beetles escaped, were killed

155 accidentally, or could not have their sex identified accurately during the experiment, and were

156 therefore excluded from analyses of reproduction, weight, and lifespan (57 excluded out of

1571381 beetles). The assignment of beetles to the developmental and adult treatments was

158 random except that we tried to assign beetles of each sex from each of the 86 families equally

159 across the four treatments. The observer was blinded to the treatment of beetles during data

160 collection to avoid bias.

161

162 Data analysis

163 To determine the effects of developmental and adult temperature as well as their

164 interaction on the life-history traits (age-independent traits) and senescence (age-dependent

165 traits) of male and female seed beetles, we used Generalised Linear Mixed-effects Models

166 (GLMM) or Linear Mixed-effects Models (LMM) as appropriate. All analyses were

167 conducted in R v3.5.2 (R Development Core Team, 2011) and models were built using the

168 lme4 (Bates et al, 2014), and glmmTMB (Magnusson et al, 2017) packages. Model details for

169 each analysed trait are given in Table 1, and in Section B of the online supplement. All

170 models contained experimental block as a three-level fixed effect, and beetle family (i.e. full-

171 sibling groups) as a random effect unless mentioned otherwise. For traits measured prior to

172 the assignment of adult treatments (i.e. emergence success, development time, and emergence

173 weight), we included developmental temperature in the model as a fixed effect. For traits

174 measured after beetles were assigned to adult temperatures (i.e. adult lifespan, female fertility,

175 female lifetime reproductive success, age-dependent (daily) female fecundity, age-dependent

176 male weight, and age-dependent survival), we included both developmental and adult 
177 temperatures as well as their interactions as fixed effects. For age-dependent female fecundity

178 and age-dependent male-weight, we included adult lifespan as a fixed effect in the models to

179 account for selective disappearance of beetles. Additionally, for male and female lifespan we

180 included emergence weight as a covariate because larger seed beetles have been previously

181 shown to live longer (Fox et al, 2003). For age-dependent weight of males, emergence weight

182 was also included as a covariate, although here, as an interaction with age, because males at

183 different ages could be affected by their emergence weight in different ways.

184 We conducted two post-hoc tests to examine how developmental temperatures were

185 affecting age-dependent male weight, within each adult temperature. The first post-hoc model

186 only used data from males who experienced hot adult temperatures, to compare males in $\mathrm{AH}$

187 (ancestral developmental and hot adult) vs HH (hot developmental and hot adult) treatments.

188 The second only used data from males who experienced ancestral adult temperatures, so that

189 males in HA (hot developmental and ancestral adult) and AA (ancestral developmental and

190 ancestral adult) temperatures could be compared.

191 For female age-dependent (daily) fecundity, we additionally created three models, one

192 which allowed the slopes of different families (of full-sibs) to differ, the other which allowed

193 the slopes of different females to differ, and the third which allowed slopes of both different

194 females and different families to differ. These models were then compared using Akaike

195 information Criteria and log-likelihood ratio tests with the anova function in the stats package

196 to obtain the best fitting model. This was done to test whether different families and females

197 showed different pattern of reproductive senescence from each other.

198 For all adult traits, males and females were analysed separately because we were not

199 interested in comparing effects across the sexes (i.e. interactions with sex). For age-

200 independent traits, where models contained interactions, we ran a "full" model with the

201 interactions, as well as a "main-effects" model (if the interactions in the full model were non-

202 significant). The main-effects models excluded non-significant interactions to allow accurate 
203 interpretation of the main-effects (Engqvist, 2005). For all linear models, residuals were

204 checked visually to ensure they met assumptions of normality and homoscedasticity. When

205 they did not, the response variable was transformed. To test for overdispersion in our models,

206 we used the function simulateResiduals in the package DHARMa (Hartig 2020). Where there

207 was evidence for over-dispersion (i.e. for female lifetime reproductive success), we fitted an

208 observation level random effect (Harrison, 2014). To test whether the effects of

209 developmental temperatures were consistent across all blocks, analyses for age-independent

210 traits were followed by post-hoc pairwise comparisons of hot and ancestral developmental

211 temperatures within each block. These comparisons were done using Tukey's test in the

212 emmeans package (Lenth et al, 2019). Effect sizes were calculated as "Hedge's g" for all two-

213 group comparisons (following equations (1) and (2) in Nakagawa \& Cuthill, 2007).

\section{Results}

216 Our analyses indicated a range of effects of developmental and adult temperature on male and

217 female traits. We describe these results below, and provide a summary in Table 2, with

218 complete model outputs for all analyses presented in the supplementary material (Tables S3 219 S18).

Age-independent traits

222 Hot temperatures caused lower emergence success, faster development, and lower

223 emergence weight in beetles, than ancestral temperatures. Specifically, hot developmental

224 temperature reduced the emergence success of beetles $(\mathrm{P}<0.001$, Table S3): 676 out of 864

225 eggs (78\%) emerged as adult beetles from the ancestral developmental temperature, while 705

226 out of 1439 eggs (49\%) emerged as adult beetles from the hot developmental temperature.

227 Both males and females that experienced hot developmental temperatures had a shorter 


\section{8}

229

230

231

232

233

234

235

236

237

238

239

240

242

243

development time (mean \pm SE: males $=23.1 \pm 0.1$, females $=23.5 \pm 0.2$ days $)$ than those

experiencing ancestral developmental temperatures (mean $\pm \mathrm{SE}$ : males $=37.8 \pm 0.2$, females $=$ $37.99 \pm 0.2$ days $)(\mathrm{P}<0.001$ for both males and females, Hedge's g: males $=4.41$, females $=$ 4.962, Table S4). Further, both males and females which developed in the hot temperature had a lower emergence weight $($ mean \pm SE: males $=3.510 \pm 0.030$, females $=4.710 \pm 0.039$ $\mathrm{mg}$ ) than those developing in the ancestral temperature (mean \pm SE: males $=3.750 \pm 0.030$, females $=5.760 \pm 0.042 \mathrm{mg})(\mathrm{P}<0.001$ for both sexes, Hedge's g: males $=0.436$, females $=$ 1.4, Table S5).

After controlling for the positive effect of emergence weight $(\mathrm{P}<0.001$, Section $\mathrm{E}$ in supplement) there were contrasting effects of hot temperatures in the developmental versus adult stage on adult lifespan. For both males and females, hot developmental temperatures increased adult lifespan (Males: Hedge's g= 0.10; $\mathrm{P}=0.005$, Females: Hedge's g= 0.06; P= 0.036). In contrast, hot adult temperatures decreased male and female adult lifespan (Males: Hedge's g= 4.820; $\mathrm{P}<0.001$, Females: Hedge's g= 2.493; $\mathrm{P}<0.001$ ) (Figure 1, Tables S6 and S7). There was no significant interaction between developmental temperature and adult temperature on adult lifespan on either males $(\mathrm{P}=0.251)$, or females $(\mathrm{P}=0.531)$.

Females that developed in hot temperatures were less likely to be fertile than females which developed in ancestral temperatures $(15.5 \%$ of females from the hot developmental temperature did not lay any eggs compared to $0.6 \%$ of females from the ancestral developmental temperature, $\mathrm{P}<0.001$, Table $\mathrm{S} 8)$. Neither adult temperature on its own $(\mathrm{P}=$ 0.119), nor the interaction between developmental and adult temperatures $(\mathrm{P}=0.986)$, had a significant effect on female fertility. In contrast, both hot developmental $(\mathrm{P}<0.001)$ and hot adult $(\mathrm{P}<0.001)$ temperatures reduced the Lifetime Reproductive Success (LRS) of females, compared to ancestral temperatures (Figure 2, Table S9). Although, developmental temperatures (Hedge's $g=0.945$ ) had a greater effect than adult temperature (Hedge's $g=$ 
253

254

255

256

257

258

259

260

261

262

263

264

265

266

267

268

269

270

271

272

273

275

276

277

278

0.241) on the LRS of females. There was no effect of the interaction between developmental and adult temperatures on female LRS $(\mathrm{P}=0.595)$.

The effects of developmental environments seen in the results above were consistently found within each block, except for male and female adult lifespan (Table S10).

\section{Age-dependent traits}

Females that experienced either hot developmental or hot adult temperatures showed a steeper decline in age-dependent (daily) fecundity as they aged compared to females that experienced ancestral temperatures at either stage (for both stages $\mathrm{P}<0.001$; Table S11).

Females from hot adult temperatures laid a higher number of eggs than females from ancestral adult temperatures at ages one (Hedge's $g=0.82$ ), two (Hedge's $g=0.50)$, and three (Hedge's $g=0.134$ ) days. After day 3, the effect sizes showed the opposite pattern i.e. females from ancestral adult temperature laid more eggs (Table S12). There was no three-way interaction between developmental temperature, adult temperature, and age (as either linear $(\mathrm{P}=0.525)$ or quadratic $(\mathrm{P}=0.226))$ to affect the age-dependent (daily) fecundity (Figure 3; Table S11).

The model which allowed the slopes for age-dependent (daily) fecundity to vary between families and between females, provided a better fit to the data than models which allowed only the slopes of different families (of full-sibs) to vary, or only the slopes of different individuals to vary, or only the intercepts of families and individuals to vary (Table S13). This suggests both significant between-family and between-individual variation in female reproductive senescence rates.

There was a significant effect of the three-way interaction between developmental and adult temperatures, and age, on age-dependent male weight $(\mathrm{P}<0.001$, Table S14, Figure 4). Post-hoc models, which analysed age-dependent weight data for hot adult and ancestral adult treatments separately (Tables S15, S16), each revealed an interaction between developmental temperature and age. Specifically, in both hot (Table S15) and ancestral (Table S16) adult 
environments, males who experienced hot temperature during development had a lower rate

280 of decline in weight with age compared to males who experienced ancestral temperatures

281 during development. The difference in average rate of decline in weight per day was greater

282 between $\mathrm{HH}$ and $\mathrm{AH}$ treatments ( $0.049 \mathrm{mg}$ per day) than between AA and HA treatments

283 (0.018 mg per day) (Tables S15, S16).

284 When age-dependent changes in weight were binned by lifespan (Figure S1), they

285 showed that heavier individuals lived longer (See Section E in Supplement). This suggests

286 that the apparent increase in average weight seen in late adult life (evidenced by a significant

287 quadratic effect of age in Table S14 and increase in weight towards the end of life in Figure 4)

288 is due to selective disappearance of lighter beetles (Effect of lifespan: $\mathrm{P}<0.001$ ).

289 For both males (Table S17, Figure 5) and females (Table S18, Figure 6), age-

290 dependent mortality (survival senescence) was affected by adult temperature (Males: $\mathrm{P}<$

291 0.001; Females: $\mathrm{P}<0.001$ ), but not developmental temperature (Males: $\mathrm{P}=0.210$; Females:

$292 \mathrm{P}=0.590$ ), nor by an interaction between developmental and adult temperature (Males: $\mathrm{P}=$

293 0.590; Females: $\mathrm{P}=0.820)$.

\section{Discussion}

Early and late life environments can interact in complex ways to shape adult traits.

297 Consequently, the results of studies testing the effects of exposure to favourable or

unfavourable early life conditions both during the development and adulthood are mixed. To

302 combination of stressful/hot temperatures and benign/ancestral temperatures. We then

303 measured a range of age-independent and age-dependent traits in both males and females. We 
304 found that while female reproductive traits were affected negatively by stressful

305 developmental temperature, somatic traits, such as lifespan and survival senescence, were

306 affected negatively by stressful adult temperature, and weight senescence was affected by an

307 interaction between these environments.

308 We found that individuals experiencing hot/stressful temperatures during development

309 emerged sooner as adults than those experiencing ancestral temperatures, supporting the

310 metabolic theory of ecology of a faster pace of life (Clarke, 2006). However, accelerated

311 development caused by high temperatures came with costs, such as lower body weight at

312 emergence (which is well known to occur in ectotherms: Zuo et al, 2012), and lower

313 emergence success. Additionally, in females, hot developmental temperatures resulted in

314 reduced reproductive performance (lower LRS and fertility, faster reproductive senescence).

315 These results support the silver-spoon hypothesis for female reproduction, suggesting that

316 independent of the adult environment, favourable developmental environments increase

317 female fitness (see also Cooper \& Kruuk, 2018; Sanghvi et al, 2021).

Additionally, when exposed to hot/stressful adult temperatures, females had higher

319 early adult life reproduction (on Days 1 to 3), but shorter lifespans and faster reproductive

320 senescence. These findings support classic life-history theory (Partridge 1987; Stearns, 1989)

321 which proposes a trade-off between early and late life reproduction (Reed et al, 2008), and

322 between survival and reproduction (Kirkwood \& Rose, 1999; Marshall et al, 2017). However,

323 our results contrast with a previous study investigating the effects of the developmental

324 density experienced by seed beetles (Sanghvi et al 2021), which showed no effect of high

325 density on the trade-off between female early and late life reproduction, or between female

326 reproduction and survival. This suggests that trade-offs between early and late adult life traits

327 are specific to, and mediated by, the type of environmental parameter being manipulated (e.g.

328 Hammers et al, 2013). In the presence of high temperature, such trade-offs appear to be 
common across taxa, including seed beetles (Berger et al, 2017; Kim et al, 2020). There are

330 several potential explanations for such patterns. For example, individuals experiencing hot

331 temperatures may adopt a "live-fast die-young" life-history strategy (Robinson et al, 2006).

332 Here, if hot temperatures decrease expected future reproduction and survival, this would be

333 expected to trigger females to terminally invest in early reproduction (Clutton-Brock, 1984),

334 although this increased early life investment would lead to faster senescence in later life (e.g.

335 Gribble et al, 2018). Alternatively, individuals exposed to cooler temperatures might show

336 reduced survival senescence because during early adult life they allocate resources to somatic

337 maintenance rather than reproduction (Kirkwood \& Austad, 2000). It is also possible that

338 temperature affects these traits independently, and that the correlations between survival and

339 reproduction are non-causal.

340 Hot adult temperatures lead to lower adult lifespan and higher age-dependent mortality

341 (survival senescence) in both males and females. The lack of a sex-specific effect on overall

342 survival is not surprising since, again, high temperatures in ectotherms are known to affect

343 longevity as a consequence of increased metabolism (Brown et al, 2004), which is likely to

344 affect males and females in a similar way. More surprising, perhaps, is that the developmental

345 environment did not also affect these somatic traits in a deleterious way. A reason for this

346 could be that selective disappearance of poor quality individuals at the developmental stage of

347 led to an average increase in adult lifespan in hot temperatures, especially in females (See

348 section D in supplement for more information). Another reason may be that somatic traits are

349 only affected by current environments, or that organisms are able to better compensate for

350 poor somatic traits than for reproductive traits, after experiencing unfavourable developmental

351 environments.

352 In contrast to the other traits, we found that early and late environments interacted to

353 affect age-dependent changes in male weight. This interaction was due to the differences in 
354 age-dependent decline in weight between hot and ancestral developmental temperature being

355 greater when adult temperature are hot compared to when they are ancestral (Table S15, S16).

356 Additionally, males who experienced hot temperature at both stages, showed a slower rate of

357 age-dependent loss in weight (Table S15) compared to males who experienced favourable

358 developmental but hot adult temperatures. This result is consistent with the beneficial

359 acclimation hypothesis (Wilson \& Franklin, 2002), which is a form of adaptive plasticity.

360 Although, because the absolute differences in the rate of weight loss between males in these

361 treatments of our study is low (only $0.049 \mathrm{mg}$ per day), whether this result is biologically

362 meaningful, remains unknown. Evidence for beneficial acclimation due to an interaction

363 between adult and developmental environments (West-Eberhard, 2003) has been commonly

364 found in species where temperature is manipulated (Leroi et al, 1994; Geister \& Fischer,

365 2007; Reviewed in Wilson \& Franklin, 2002). However, previous studies looking at age-

366 dependent traits have not found any evidence for beneficial acclimation effects when

367 manipulating foraging environments (Briga et al, 2019), or diet and temperature (Min et al,

368 2021). A testable hypothesis for why we found some evidence for beneficial acclimation

369 could be that the allocation of resources towards somatic (i.e. body weight) maintenance, by

370 males who experience developmental stress, occurs at the expense of investment in

371 reproduction.

372 A recent study (Duxbury \& Chapman, 2020), which aimed to test between the silver-

373 spoon and environmental matching hypotheses, manipulated developmental and adult

374 nutrition, and found that female reproductive senescence was affected by an interaction

375 between developmental and adult diets. However, another study that manipulated both adult

376 and developmental temperatures in Drosophila found results similar to ours (Min et al, 2020).

377 Specifically, they found that adult temperature had a greater effect on age-dependent survival

378 than developmental temperature, and that hot adult temperatures were deleterious for adult 
survival senescence. However, they also found an interaction of adult and developmental

380 temperatures to affect age-dependent fecundity deleteriously, which we did not. One reason

381 why we did not find such interactions could be due to the kind of environmental variable that

382 was manipulated (temperature in our study, diet in Duxbury \& Chapman, 2020) and different

383 biology of the species studied.

384 Finally, we also found two population-level patterns in senescence which could have

385 important ecological and evolutionary consequences. First, there were significant differences

386 in rates of reproductive senescence between females, as well as between families (of full-

387 sibs). This was evidenced by models which allowed the slopes of both, different females and

388 families to vary, providing a better fit to the data than models which did not. Individual-level

389 variation in senescence has been shown previously in wild animals (Bouwhuis et al, 2010),

390 and is essential for traits (in our case, reproductive senescence) to evolve via natural selection.

391 Further, the differences in rates of reproductive senescence between families suggest this trait

392 is heritable and thus able to evolve. Second, we found evidence for selective disappearance of

393 lighter males with increasing age. This may have masked individual-level decreases in weight

394 due to heavier individuals surviving longer. Such evidence of individual-level patterns of

395 senescence being masked by population patterns of ageing due to selective disappearance of

396 individuals has previously only been shown in vertebrates (Bouwhuis et al, 2009; Hayward et

397 al, 2013).

\section{Conclusion}

Ours is one of the first studies to test how heat stress experienced at different life-

401 stages interacts to affect individual life-histories and senescence. We show that depending on

402 the trait and the sex measured, either developmental, adult, or the interaction between both

403 environments can affect the resulting phenotype. This suggests that the way environments 
404 affect an individual's phenotypic responses is complex and shows that each trait can follow

405 different trajectories, providing support to different aspects and hypotheses of life-history

406 theory. In consequence, we highlight the importance of measuring fitness-related traits

407 throughout an organism's life, as well as measuring both physiological and life-history

408 components of fitness in order to understand the holistic effects of environments on

409 individuals. Considering that the adult environment might have stronger influence than

410 developmental environments on traits which are not direct measures of reproduction, we

411 suggest that studies should integrate the effects of early and late life environments to avoid

412 biased results, as well as measure a diverse range of life-history and physiological traits. If

413 traits change differently over time in different environments, it is crucial that studies measure

414 these traits throughout the lifetime of organisms.

\section{References}

417 ADLER, M., TELFORD, M. \& BONDURIANSKY, R. 2016. Phenotypes optimized for 418 early $\square$ life reproduction exhibit faster somatic deterioration with age, revealing a latent 419 cost of high condition. Journal of Evolutionary Biology, 29, 2436-2446.

\section{BAHRNDORFF, S., GERTSEN, S., PERTOLDI, C. \& KRISTENSEN, T. N. 2016.} melanogaster using behavioural assays. Biological Journal of the Linnean Society,

424 BALBONTÍN, J. \& MØLLER, A. 2015. Environmental conditions during early life accelerate the rate of senescence in a short $\square$ lived passerine bird. Ecology, 96, 948959.

BATES, D., MACHLER, M., BOLKER, B. and WALKER, S., 2014. Fitting linear mixed- 
BATESON, P., GLUCKMAN, P. \& HANSON, M. 2014. The biology of developmental

BEAMAN, J. E., WHITE, C. R. \& SEEBACHER, F. 2016. Evolution of plasticity: \& Evolution, 31, 237-249.

BECK, C. W. \& BLUMER, L. S. 2011. A handbook on bean beetles, Callosobruchus maculatus. National Science Foundation.

BERGER, D., STANGBERG, J., GRIESHOP, K., MARTINOSSI, I. and ARNQVIST, G., 2017. Temperature effects on life-history trade-offs, germline maintenance and

BOUWHUIS, S., CHARMANTIER, A., VERHULST, S. \& SHELDON, B. C. 2010. growing old: selective disappearance and the partitioning of senescence to stages 
452

453

454

455

456

457

458

460

461

462

463

464

465

466

467

468

469

470

471

472

473

474

475

BRIGA, M., KOETSIER, E., BOONEKAMP, J. J., JIMENO, B. \& VERHULST, S. 2017.

Food availability affects adult survival trajectories depending on early developmental conditions. Proceedings of the Royal Society B: Biological Sciences, 284, 20162287.

BROWN, J.H., GILLOOLY, J.F., ALLEN, A.P., SAVAGE, V.M. \& WEST, G.B., 2004. Toward a metabolic theory of ecology. Ecology, 85, 1771-1789.

CEBALLOS, C.P. \& VALENZUELA, N., 2011. The role of sex-specific plasticity in shaping sexual dimorphism in a long-lived vertebrate, the snapping turtle Chelydra serpentina. Evolutionary Biology, 38, 163-181.

CLARKE, A. 2006. Temperature and the metabolic theory of ecology. Functional Ecology, $20,405-412$.

CLEAL, J. K., POORE, K. R., BOULLIN, J. P., KHAN, O., CHAU, R., HAMBIDGE, O., TORRENS, C., NEWMAN, J. P., POSTON, L., NOAKES, D. E., HANSON, M. A. \& GREEN, L. R. 2007. Mismatched pre- and postnatal nutrition leads to cardiovascular dysfunction and altered renal function in adulthood. Proceedings of the National Academy of Sciences, 104, 9529-9533.

CLUTTON-BROCK, T. H. 1984. Reproductive Effort and Terminal Investment in Iteroparous Animals. The American Naturalist, 123, 212-229.

COOPER, E. B. \& KRUUK, L. E. 2018. Ageing with a silver $\square$ spoon: A meta $\square$ analysis of the effect of developmental environment on senescence. Evolution Letters, 2, 460-471.

DEERE, J. A. \& CHOWN, S. L. 2006. Testing the beneficial acclimation hypothesis and its alternatives for locomotor performance. The American Naturalist, 168, 630-644.

DESCAMPS, S., BOUTIN, S., BERTEAUX, D., MCADAM, A. G. \& GAILLARD, J. M. 2008. Cohort effects in red squirrels: the influence of density, food abundance and temperature on future survival and reproductive success. Journal of Animal Ecology, 
DMITRIEW, C. \& ROWE, L., 2007. Effects of early resource limitation and compensatory growth on lifetime fitness in the ladybird beetle (Harmonia axyridis). Journal of

DOUGHERTY, L. R., VAN LIESHOUT, E., MCNAMARA, K. B., MOSCHILLA, J. A., ARNQVIST, G. \& SIMMONS, L. W. 2017. Sexual conflict and correlated evolution between male persistence and female resistance traits in the seed beetle

DUXBURY, E. M. L. and CHAPMAN, T. 2019. Sex-Specific responses of Life Span and Fitness to Variation in Developmental Versus Adult Diets in Drosophila

ENGQVIST, L. 2005. The mistreatment of covariate interaction terms in linear model analyses of behavioural and evolutionary ecology studies. Animal Behaviour, 70, 967Inbreeding-environment interactions for fitness: complex relationships between Ecology, 25, 25-43. mortality rates in two seed beetle species. Functional Ecology, 17, 619-626. 
500 GEISTER, T.L. \& FISCHER, K., 2007. Testing the beneficial acclimation hypothesis:

501 temperature effects on mating success in a butterfly. Behavioral Ecology, 18, 658-664.

502 GLUCKMAN, P. D., HANSON, M. A. \& SPENCER, H. G. 2005. Predictive adaptive

503 responses and human evolution. Trends in Ecology \& Evolution, 20, 527-533.

504 GRAFEN, A. 1988. On the uses of data on lifetime reproductive success. In: Clutton-Brock,

505 T.H. (ed) Reproductive success. Chicago University Press, Chicago, pp 454-471

506 GRIBBLE, K. E., MORAN, B. M., JONES, S., COREY, E. L. \& MARK WELCH, D. B.

507 2018. Congeneric variability in lifespan extension and onset of senescence suggest

508 active regulation of aging in response to low temperature. Experimental Gerontology,

$509 \quad 114,99-106$.

510 HAMMERS, M., RICHARDSON, D., BURKE, T. \& KOMDEUR, J. 2013. The impact of

511 reproductive investment and early $\square$ life environmental conditions on senescence:

512 support for the disposable soma hypothesis. Journal of Evolutionary Biology, 26,

$513 \quad 1999-2007$.

514 HARTIG, F. 2020. DHARMa: Residual diagnostics for hierarchical (multi-level/mixed)

515 regression models. R Package version 0.3.2.0.http://florianhartig.github.io/DHARMa/

516 HARRISON, X. A. 2014. Using observation-level random effects to model overdispersion in 517 count data in ecology and evolution. PeerJ, 2, e616.

518 HAYWARD, A. D. \& LUMMAA, V. 2013. Testing the evolutionary basis of the predictive

519 adaptive response hypothesis in a preindustrial human population. Evolution,

$520 \quad$ Medicine, and Public Health, 2013, 106-117.

521 HAYWARD, A. D., WILSON, A. J., PILKINGTON, J. G., CLUTTON $\square$ BROCK, T. H.,

522 PEMBERTON, J. M. \& KRUUK, L. E. 2013. Reproductive senescence in female

523 Soay sheep: variation across traits and contributions of individual ageing and selective 
disappearance. Functional Ecology, 27, 184-195.

525 HELLE, H., KOSKELA, E. \& MAPPES, T. 2012. Life in varying environments:

526 experimental evidence for delayed effects of juvenile environment on adult life

527 history. Journal of Animal Ecology, 81, 573-582.

528 HOOPER, A. K., SPAGOPOUlOU, F., WYLDE, Z., MAKLAKOV, A. A. \&

529 BONDURIANSKY, R. 2017. Ontogenetic timing as a condition-dependent life history

530 trait: High-condition males develop quickly, peak early, and age fast. Evolution, 71,

$531 \quad 671-685$.

532 HUEY, R. B., BERRIGAN, D., GILCHRIST, G. W. \& HERRON, J. C. 1999. Testing the 533 adaptive significance of acclimation: a strong inference approach. American Zoologist,

$534 \quad 39,323-336$.

535 HUNT, J., BROOKS, R., JENNIONS, M. D., SMITH, M. J., BENTSEN, C. L. \&

536 BUSSIERE, L. F. 2004. High-quality male field crickets invest heavily in sexual

537 display but die young. Nature, 432, 1024.

538 IGLESIAS-CARRASCO, M., BROOKES, S., KRUUK, L.E. \& HEAD, M.L., 2020. The

539 effects of competition on fitness depend on the sex of both competitors. Ecology and

$540 \quad$ Evolution, 10, 9808-9826.

541 KELLERMANN, V., VAN HEERWAARDEN, B. \& SGRÒ, C. M. 2017. How important is

542 thermal history? Evidence for lasting effects of developmental temperature on upper

543 thermal limits in Drosophila melanogaster. Proceedings of the Royal Society B:

$544 \quad$ Biological Sciences, 284, 20170447.

545 KIM, K.E., JANG, T. \& LEE, K.P., 2020. Combined effects of temperature and

546 macronutrient balance on life-history traits in Drosophila melanogaster: implications

547 for life-history trade-offs and fundamental niche. Oecologia, 193. 
548 KIRKWOOD, T. B. \& AUSTAD, S. N. 2000. Why do we age? Nature, 408, 233.

549 KIRKWOOD, T. B. \& ROSE, M. R. 1991. Evolution of senescence: late survival sacrificed

$550 \quad$ for reproduction. Philosophical Transactions of the Royal Society of London, 332, 15-

55124.

552 KLEINTEICH, A., WILDER, S. M. \& SCHNEIDER, J. M. 2015. Contributions of juvenile

553 and adult diet to the lifetime reproductive success and lifespan of a spider. Oikos, 124,

$554 \quad 130-138$.

555

KLEPSATEL, P., KNOBLOCHOVÁ, D., GIRISH, T. N., DIRCKSEN, H. \& GÁLIKOVÁ,

556 M. 2020. The influence of developmental diet on reproduction and metabolism in

557 Drosophila. BMC Evolutionary Biology, 20, 93.

558 KLEPSATEL, P., GIRISH, T. N., DIRCKSEN, H. \& GÁLIKOVÁ, M. 2019. Reproductive

559 fitness of Drosophila is maximised by optimal developmental temperature. Journal of

$560 \quad$ Experimental Biology, 222.

561 KRAUSE, E. T., KRÜGER, O. \& SCHIELZETH, H. 2017. Long-term effects of early

562 nutrition and environmental matching on developmental and personality traits in zebra

563 finches. Animal Behaviour, 128, 103-115.

564 KRISTENSEN, T. N., HOFFMANN, A. A., OVERGAARD, J., SøRENSEN, J. G.,

565 HALLAS, R. \& LOESCHCKE, V. 2008. Costs and benefits of cold acclimation in

566 field-released Drosophila. Proceedings of the National Academy of Sciences, 105,

$567 \quad 216-221$.

568 LENTH, R., SINGMANN, H., LOVE, J., BUERKNER, P., HERVE, M. 2019. Package

$569 \quad$ "emmeans.” CRAN v1.6.3.

570 LEROI, A.M., BENNETT, A.F. \& LENSKI, R.E., 1994. Temperature acclimation and

571 competitive fitness: an experimental test of the beneficial acclimation 
573 MADSEN, T. \& SHINE, R. 2000. Silver spoons and snake body sizes: prey availability early

574 in life influences long $\square$ term growth rates of free $\square$ ranging pythons. Journal of Animal

$575 \quad$ Ecology, 69, 952-958.

576

577

578

MAGNUSSON, A., SKAUG, H., NIELSEN, A., BERG, C., KRISTENSEN, K., MAECHLER, M., VAN BENTHAM, K., BOLKER, B., BROOKS, M., \& BROOKS, M.M. 2017. Package 'glmmTMB'. R Package V 0.2. 0.

MAKLAKOV, A. A., HALL, M. D., SIMPSON, S. J., DESSMANN, J., CLISSOLD, F. J., ZAJITSCHEK, F., LAILVAUX, S. P., RAUBENHEIMER, D., BONDURIANSKY, R. \& BROOKS, R. C. 2009. Sex differences in nutrient-dependent reproductive ageing. Aging Cell, 8, 324-30.

MARAIS, E. \& CHOWN, S.L., 2008. Beneficial acclimation and the Bogert effect. Ecology Letters, 11, 1027-1036.

MARSHALL, H. H., VITIKAINEN, E. I., MWANGUHYA, F., BUSINGE, R., KYABULIMA, S., HARES, M. C., INZANI, E., KALEMA $\square Z I K U S O K A, ~ G .$, MWESIGE, K. \& NICHOLS, H. J. 2017. Lifetime fitness consequences of early $\square$ life ecological hardship in a wild mammal population. Ecology and Evolution, 7, 17121724.

METCALFE, N. B., and P. MONAGHAN. 2001. Compensation for a bad start: grow now, pay later? Trends in Ecology \& Evolution, 16, 254-260.

MIN, K.W., JANG, T. and LEE, K.P. 2020. Thermal and nutritional environments during development exert different effects on adult reproductive success in Drosophila melanogaster. Ecology and evolution, 11, 443-457.

MONAGHAN, P. 2008. Early growth conditions, phenotypic development and environmental 

Sciences, 363, 1635-1645.

MÜLLER, T., KÜLL, C. L. \& MÜLLER, C. 2016. Effects of larval versus adult density conditions on reproduction and behavior of a leaf beetle. Behavioral Ecology and Sociobiology, 70, 2081-2091.

NAKAGAWA, S., CUTHILL, I.C. 2007. Effect size, confidence intervals and statistical significance: a practical guide for biologists. Biological Reviews of the Cambridge Philosophical Society, 82, 591-605.

604 NUSSEY, D. H., KRUUK, L. E., MORRIS, A. \& CLUTTON-BROCK, T. H. 2007.

605 Environmental conditions in early life influence ageing rates in a wild population of red deer. Current Biology, 17, R1000-R1001.

PARTRIDGE, L. 1987. Is Accelerated Senescence a Cost of Reproduction? Functional Ecology, 1, 317-320.

PARTRIDGE, L., \& SILBY, R. 1991. Constraints in the evolution of life histories.

PIGEON, G., LOE, L. E., BISCHOF, R., BONENFANT, C., FORCHHAMMER, M.,

615 R DEVELOPMENT CORE TEAM, R. 2011. R: A language and environment for statistical computing. $\mathrm{R}$ foundation for statistical computing Vienna, Austria.

617 REED, T. E., KRUUK, L. E., WANLESS, S., FREDERIKSEN, M., CUNNINGHAM, E. J. \& 
reproduction. The American Naturalist, 171, E89-E101.

621

622

623

624

625

626

ROBINSON, M.R., PILKINGTON, J.G., CLUTTON $\square$ BROCK, T.H., PEMBERTON, J.M. \& KRUUK, L.E., 2006. Live fast, die young: trade $\square$ offs between fitness components and sexually antagonistic selection on weaponry in Soay sheep. Evolution, 60, 21682181.

ROSE, M. \& CHARLESWORTH, B. 2002. A test of evolutionary theories of senescence. Science's SAGE KE, 2002, 17.

SANTOS, M. A., CARROMEU-SANTOS, A., QUINA, A. S., SANTOS, M., MATOS, M. \& SIMÕES, P. 2021. High developmental temperature leads to low reproduction despite adult temperature. Journal of Thermal Biology, 95, p.102794

SANGHVI, K., ZAJITSCHEK, F., IGLESIAS-CARRASCO, M., HEAD, M. J. 2021. Sexand trait-specific silver-spoon effects of developmental environments, on ageing. Evolutionary Ecology, 35, 367-385.

SCHARF, I., BRAF, H., IFRACH, N., ROSENSTEIN, S., SUBACH, A. 2015. The Effects of Temperature and Diet during Development, Adulthood, and Mating on Reproduction in the Red Flour Beetle. PLoS ONE, 10(9), e0136924.

SCHARF, I., GALKIN, N. \& HALLE, S. 2015. Disentangling the consequences of growth temperature and adult acclimation temperature on starvation and thermal tolerance in the red flour beetle. Evolutionary Biology, 42, 54-62.

SCOTT, G. R. \& JOHNSTON, I. A. 2012. Temperature during embryonic development has persistent effects on thermal acclimation capacity in zebrafish. Proceedings of the National Academy of Sciences, 109, 14247.

SPAGOPOULOU, F., TEPLITSKY, C., LIND, M. I., GUSTAFSSON, L. \& MAKLAKOV, A. 2019. Silver $\square$ spoon upbringing improves early $\square$ life fitness but promotes reproductive ageing in a wild bird. Ecology Letters, 23, 994-1002. 
645 STEARNS, S. C. 1989. Trade-offs in life-history evolution. Functional Ecology, 3, 259-268.

646 STILLWELL, R. C., BLANCKENHORN, W., TEDER, T., DAVIDOWITZ, G., FOX, C. W.

647 2010. Sex Differences in Phenotypic Plasticity Affect Variation in Sexual Size

648 Dimorphism in Insects: From Physiology to Evolution. Annual Review of Entomology,

$649 \quad \mathbf{5 5}, 227-245$.

650 STILLWELL, R. C. \& FOX, C. W. 2005. Complex patterns of phenotypic plasticity: interactive effects of temperature during rearing and oviposition. Ecology, 86, 924-

TABORSKY, B. 2006. The influence of juvenile and adult environments on life-history trajectories. Proceedings of the Royal Society B: Biological Sciences, 273, 741-750.

THERNEAU, T. 2014. Coxme: Mixed-effects Cox models. R v 2.2-16. https://cran.rproject.org/web/packages/coxme/index.html

VAN DE POL, M., BRUINZEEL, L. W., HEG, D., VAN DER JEUGD, H. P. \& VERHULST, S. 2006. A silver spoon for a golden future: long $\square$ term effects of natal

VAN DE POL, M., \& VERHULST, S. 2006. Age-dependent traits: A new statistical model to separate within- and between- individual effects. American Naturalist, 167, 766-773 
669 WEST-EBERHARD, M. J. 2003. Developmental plasticity and evolution, Oxford University

$670 \quad$ Press.

671 WILSON, R. S. \& FRANKLIN, C. E. 2002. Testing the beneficial acclimation hypothesis.

672 Trends in Ecology \& Evolution, 17, 66-70.

673 WONG, J. W. \& KÖLLIKER, M. 2014. Effects of food restriction across stages of juvenile

674 and early adult development on body weight, survival and adult life history. Journal of

675 Evolutionary Biology, 27, 2420-2430.

676 WOODS, H. A. \& HARRISON, J. F. 2002. Interpreting rejections of the beneficial

677 acclimation hypothesis: when is physiological plasticity adaptive? Evolution, 56,

$678 \quad 1863-1866$.

679 ZAJITSCHEK, F., HUNT, J., JENNIONS, M.D., HALL, M.D. \& BROOKS, R.C. 2009.

680 Effects of juvenile and adult diet on ageing and reproductive effort of male and female

681 black field crickets, Teleogryllus commodus. Functional Ecology, 23, 602-611.

682 ZUO, W., MOSES, M. E., WEST, G. B., HOU, C. \& BROWN, J. H. 2012. A general model

683 for effects of temperature on ectotherm ontogenetic growth and development.

684 Proceedings of the Royal Society B: Biological Sciences, 279, 1840-1846. 
Table 1. Summary of traits and models used for analyses. DevT. =Developmental temperature, AdultT. =Adult temperature, Age= Adult age

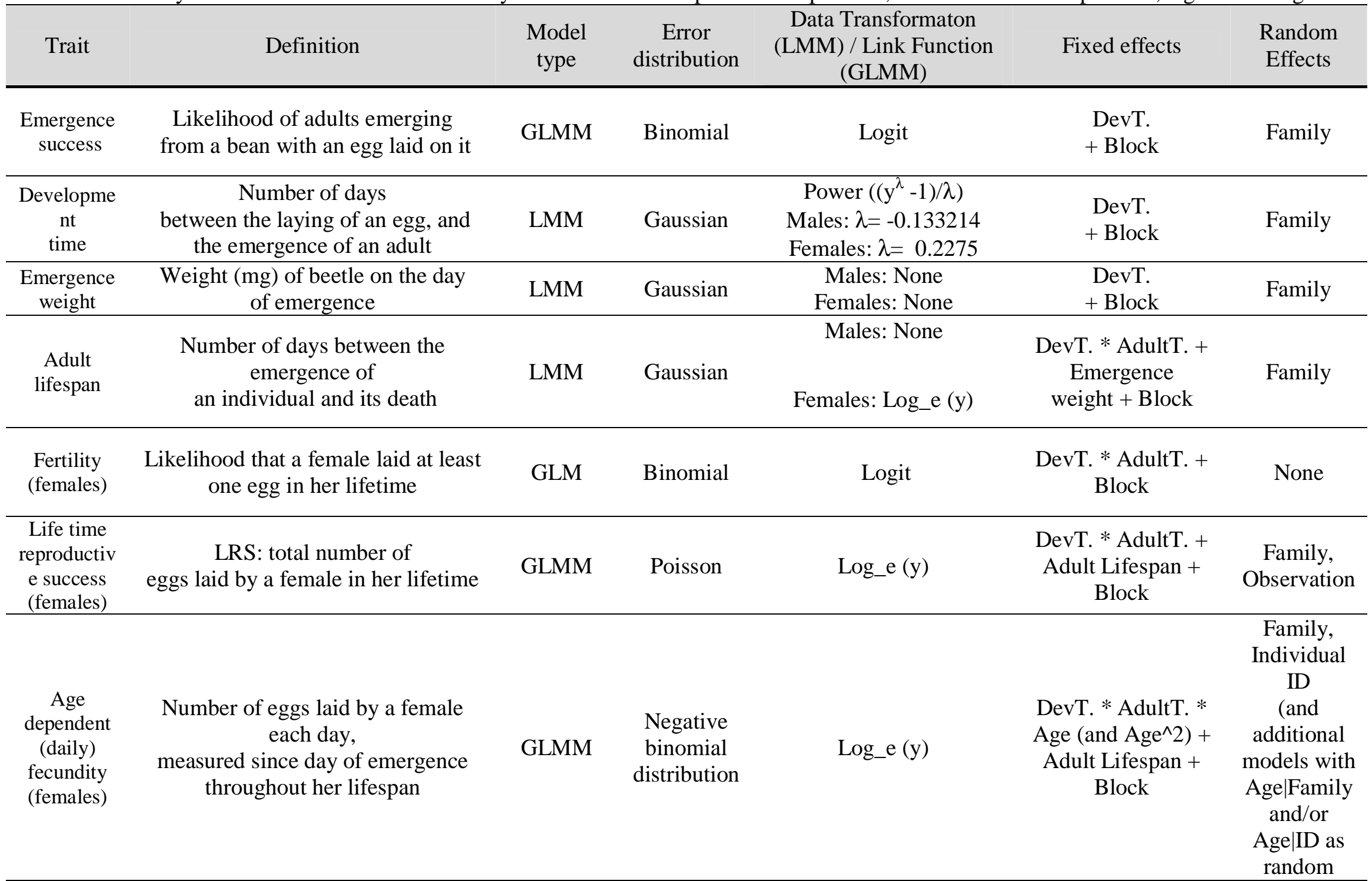


effects)

\begin{tabular}{|c|c|c|c|c|c|c|}
\hline $\begin{array}{l}\text { Age- } \\
\text { dependent } \\
\text { weight } \\
\text { (males) }\end{array}$ & $\begin{array}{c}\text { Weight }(\mathrm{mg}) \text { of males measured } \\
\text { every alternate day, since day of } \\
\text { emergence, } \\
\text { throughout his lifespan }\end{array}$ & LMM & Gaussian & None & $\begin{array}{c}\text { DevT. } * \text { AdultT. } * \\
\text { Age (and Age^2) + } \\
\text { Age*Emergence } \\
\text { weight }+ \\
\text { Adult Lifespan }+ \\
\text { Block }\end{array}$ & $\begin{array}{l}\text { Family, } \\
\text { Individual } \\
\text { ID }\end{array}$ \\
\hline $\begin{array}{l}\text { Age- } \\
\text { dependent } \\
\text { survival }\end{array}$ & $\begin{array}{l}\text { Likelihood of adult beetles dying at a } \\
\text { given adult age }\end{array}$ & $\begin{array}{l}\text { Cox- } \\
\text { Proportion } \\
\text { al } \\
\text { hazards } \\
\end{array}$ & & None & $\begin{array}{c}\text { DevT.* } \\
\text { AdultT. + Block }\end{array}$ & Family \\
\hline
\end{tabular}




\begin{tabular}{|c|c|c|c|c|c|c|c|c|c|}
\hline \multirow[b]{2}{*}{ Trait } & \multicolumn{2}{|c|}{ DevT } & \multicolumn{2}{|c|}{ Adult T } & \multicolumn{2}{|c|}{ DevT* AdultT } & \multirow[t]{2}{*}{ DevT*Age } & \multirow[t]{2}{*}{ AdultT*Age } & \multirow[t]{2}{*}{ DevT*AdultT*Age } \\
\hline & males & females & males & females & males & females & & & \\
\hline $\begin{array}{l}\text { Emergence success } \\
\quad \text { (both sexes) }\end{array}$ & \multicolumn{2}{|c|}{$\mathrm{H}<\mathrm{A}$} & & & & & & & \\
\hline Development time & $\mathrm{H}<\mathrm{A}$ & $\mathrm{H}<\mathrm{A}$ & & & & & & & \\
\hline Emergence weight & $\mathrm{H}<\mathrm{A}$ & $\mathrm{H}<\mathrm{A}$ & & & & & & & \\
\hline Adult lifespan & $\mathrm{H}>\mathrm{A}$ & $\mathrm{H}>\mathrm{A}$ & $\mathrm{H}<\mathrm{A}$ & $\mathrm{H}<\mathrm{A}$ & ns & ns & & & \\
\hline Female fertility & & $\mathrm{H}<\mathrm{A}$ & & ns & & ns & & & \\
\hline Female LRS & & $\mathrm{H}<\mathrm{A}$ & & $\mathrm{H}<\mathrm{A}$ & & ns & & & \\
\hline $\begin{array}{l}\text { Female age- } \\
\text { dependent (daily) } \\
\text { fecundity }\end{array}$ & & - & & - & & - & Yes & Yes & ns \\
\hline $\begin{array}{l}\text { Male age-dependent } \\
\text { adult weight }\end{array}$ & - & & - & & - & & Yes & - & Yes \\
\hline $\begin{array}{l}\text { Age-dependent } \\
\text { survival }\end{array}$ & ns & ns & Yes & Yes & ns & ns & & & \\
\hline
\end{tabular}




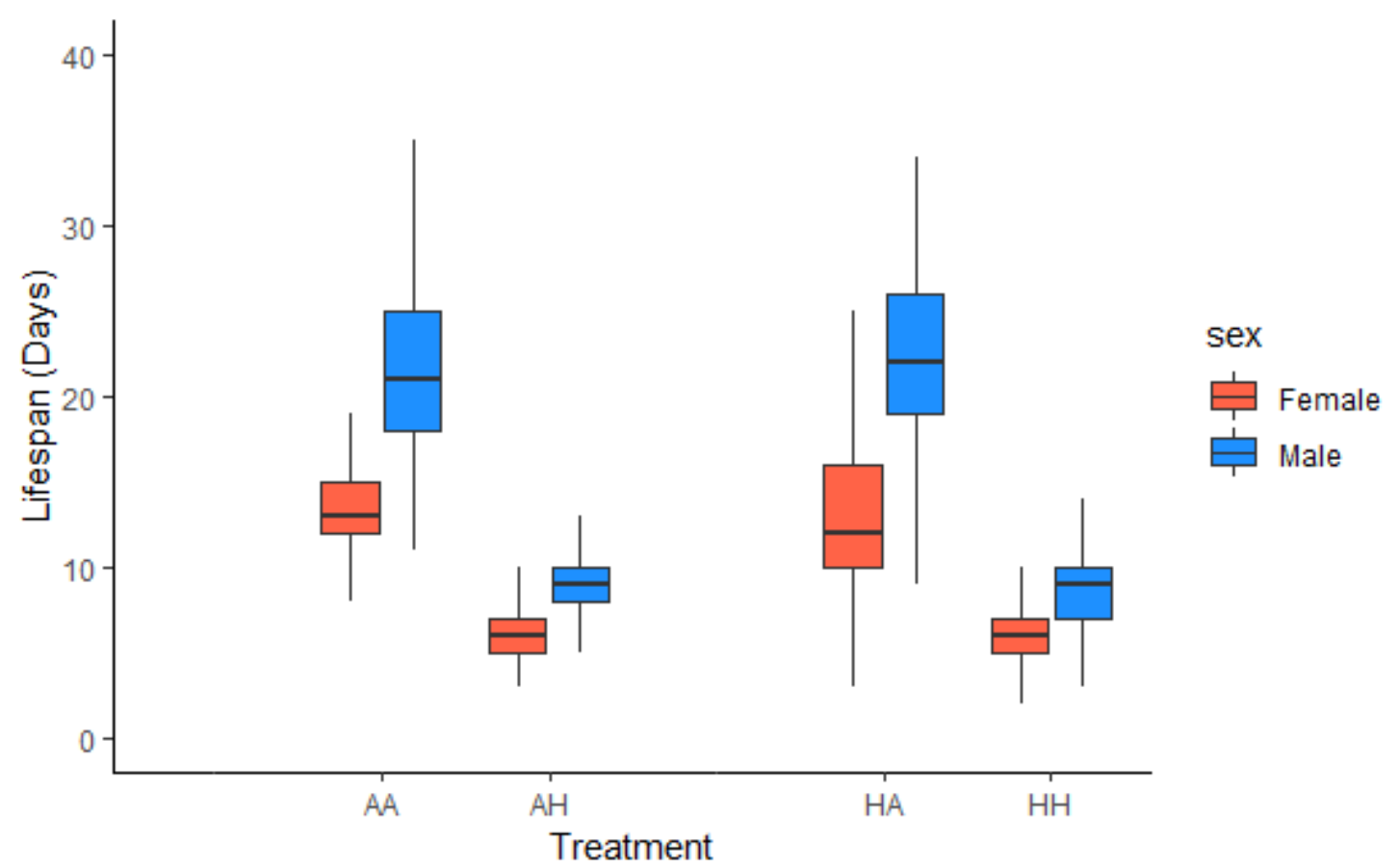

699 Figure 1. The effects of developmental and adult temperatures on female (red) and male

700 (blue) adult lifespan. Ancestral developmental and ancestral adult (AA), ancestral

701 developmental and hot adult (AH), hot developmental and hot adult $(\boldsymbol{H H})$, and hot

702 developmental and ancestral adult $(\boldsymbol{H A})$ temperatures. Median, interquartile ranges $(25,50$,

$70375 \%$ ) and upper and lower extremes presented.

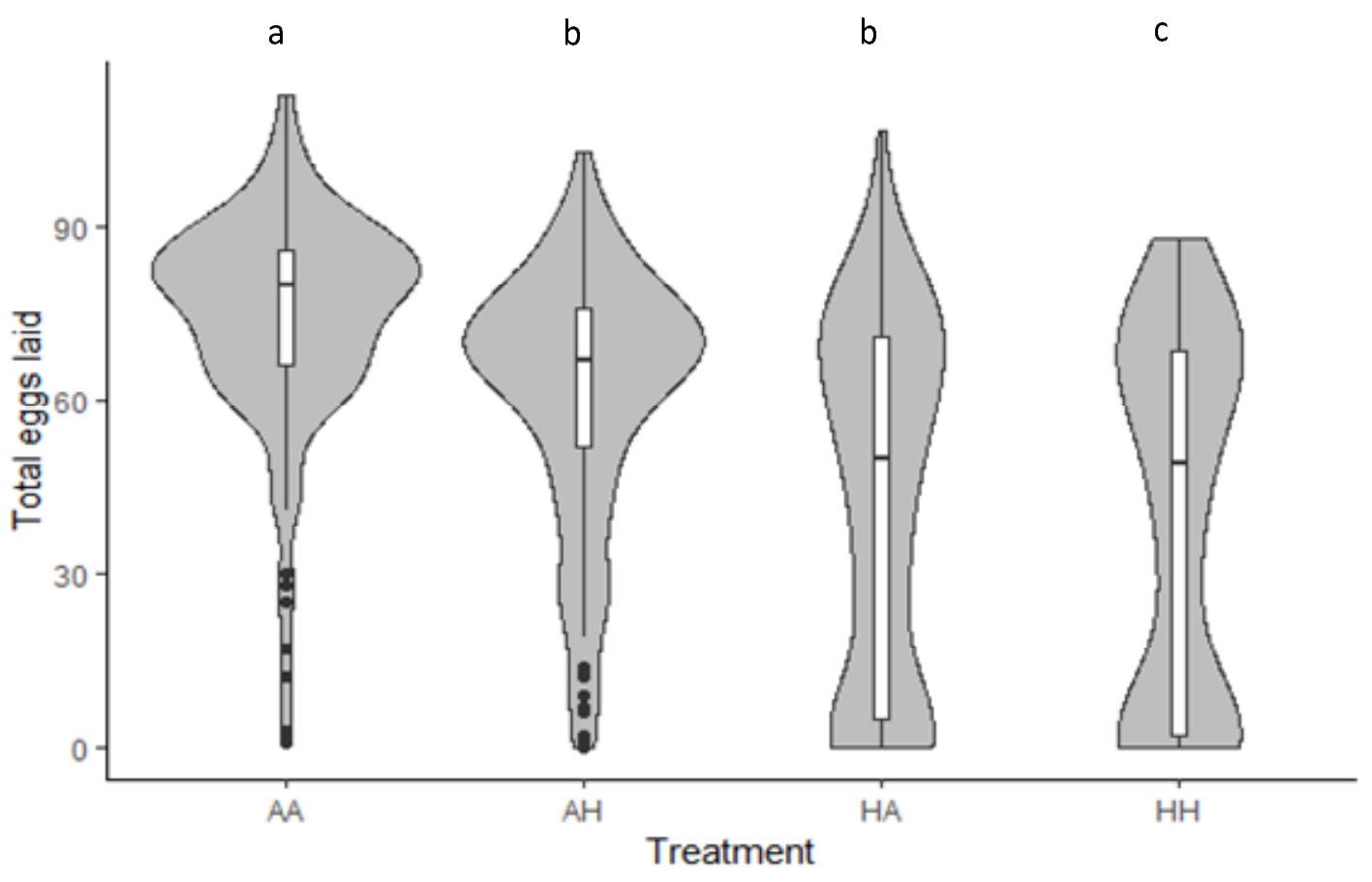


704 Figure 2. Violin plot comparing the smoothed probability density, median, interquartile

705 ranges $(25,50,75 \%)$, and upper and lower extremes presented. of the effects of developmental

706 and adult temperature on female lifetime reproductive success (LRS). Ancestral

707 developmental and ancestral adult $(\boldsymbol{A A})$, ancestral developmental and hot adult $(\boldsymbol{A H})$, hot

708 developmental and hot adult $(\boldsymbol{H H})$, and hot developmental and ancestral adult $(\boldsymbol{H A})$

709 temperatures. Letters 'a to c' denote significant differences between pairwise comparisons of

710 groups, with same letters denoting no significant difference.

711

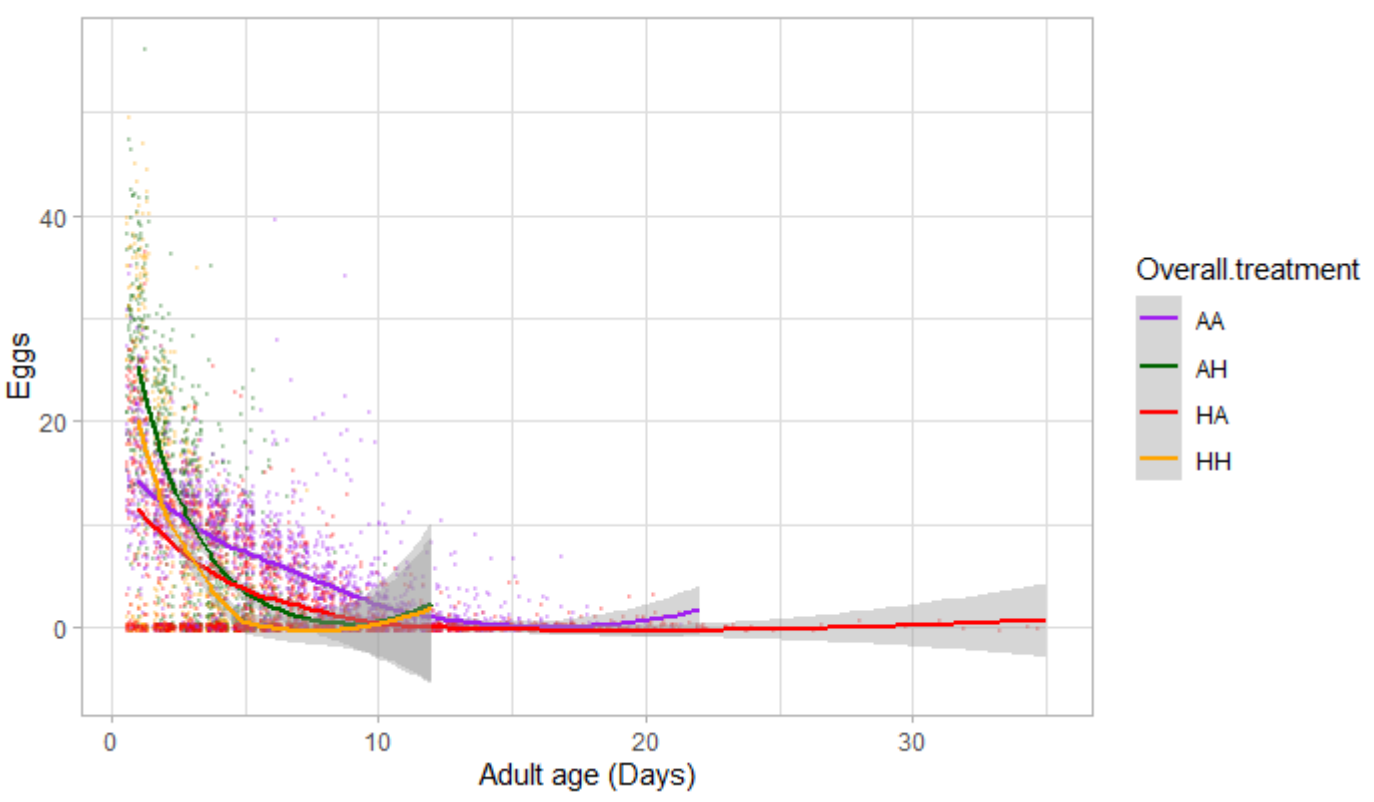

713 Figure 3. Effects of adult age on female daily fecundity for all four treatments: Ancestral

714 developmental and ancestral adult (AA-Purple), ancestral developmental and hot adult (AH-

715 Green), hot developmental and hot adult (HH-Orange), and hot developmental and ancestral

716 adult $(\boldsymbol{H A}-\mathbf{R e d})$ temperatures. Shaded regions represent $95 \%$ confidence intervals. 
bioRxiv preprint doi: https://doi.org/10.1101/2021.10.15.464502; this version posted October 18, 2021. The copyright holder for this preprint (which was not certified by peer review) is the author/funder, who has granted bioRxiv a license to display the preprint in perpetuity. It is made available under aCC-BY-ND 4.0 International license.

717

718 Figure 4. Effects of adult age on weight $(\mathrm{mg})$ in males for all four treatments of: Ancestral

719 developmental and ancestral adult (AA-Purple), ancestral developmental and hot adult (AH-

720 Green), hot developmental and hot adult (HH-Orange), and hot developmental and ancestral

adult (HA-Red $)$ temperatures. Shaded regions represent 95\% confidence intervals.

722

723

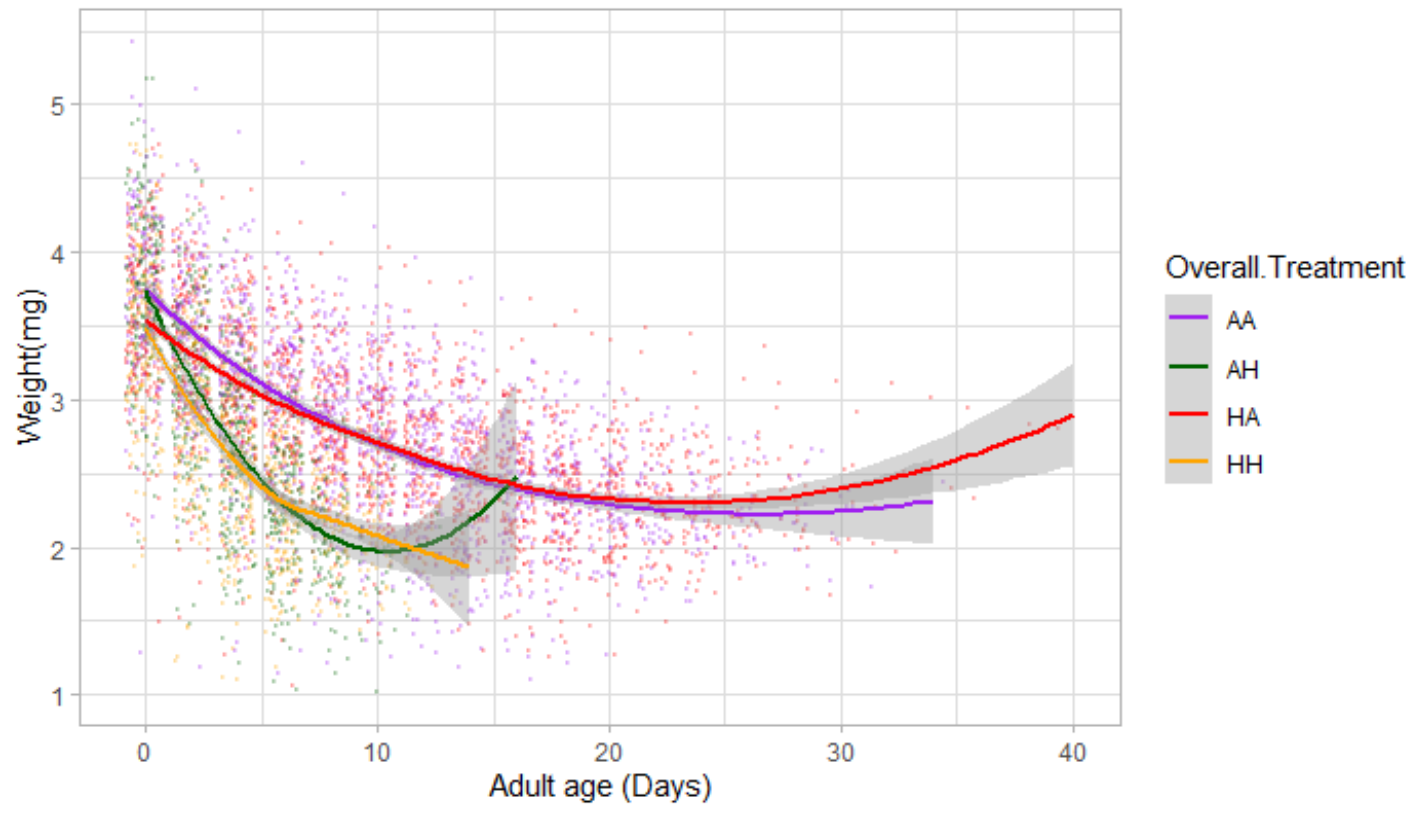

721
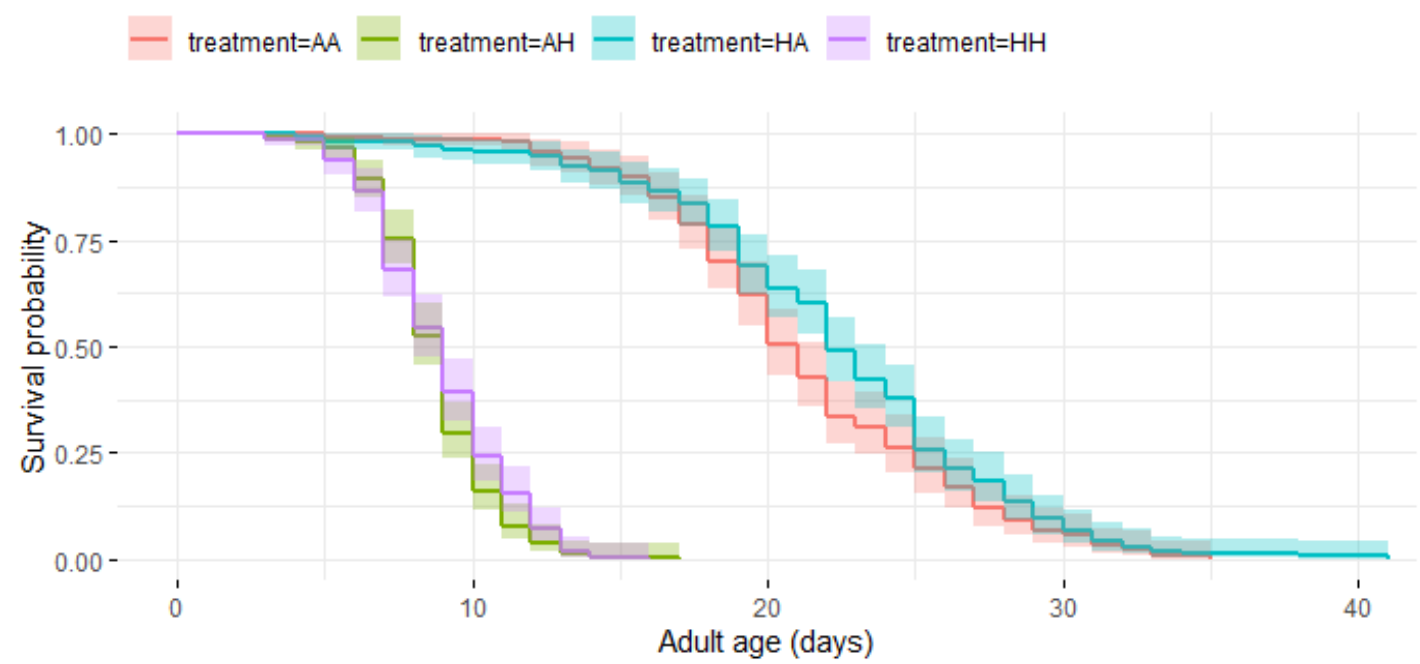

724

Figure 5. The survival probability of adult males from four treatments with increasing age,

726 namely: Ancestral developmental and ancestral adult (AA-red), ancestral developmental and

727 hot adult (AH-green), hot developmental and hot adult (HH-purple), and hot developmental 
728 and ancestral adult (HA-blue) temperatures, using Kaplan-Meier curves. Shaded regions 729 represent $95 \%$ confidence intervals.

730

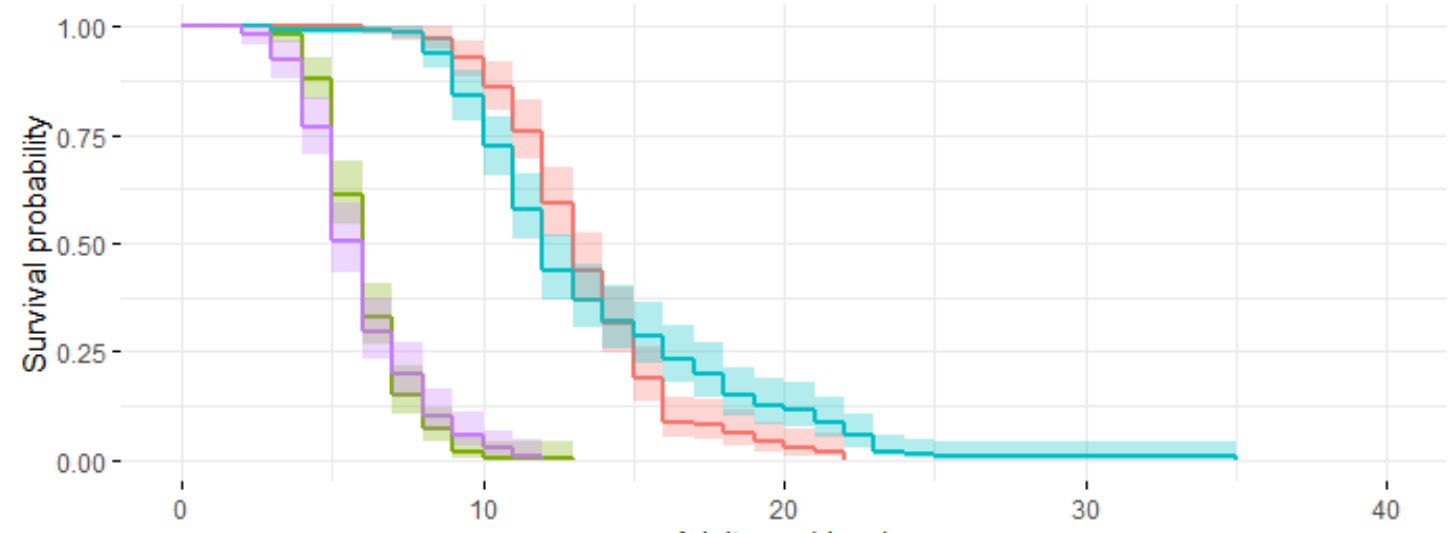

732 Figure 6. The survival probability of adult females from four treatments with increasing age,

733 namely: Ancestral developmental and ancestral adult (AA-red), ancestral developmental and

734 hot adult (AH-green), hot developmental and hot adult (HH-purple), and hot developmental

735 and ancestral adult (HA-blue) temperatures, using Kaplan-Meier curves. Shaded regions

736 represent $95 \%$ confidence intervals. 